STEM, STEAM, STREAM:

Posibilidades, reflexiones y experiencias

\title{
Aprender y crecer con STEAM: Una experiencia de diseño en el jardín de infancia
}

Recepción: 30/11/2020 | Revisión: 07/02/2021 | Aceptación: 06/08/2021 | Publicación: 01/10/2021

\section{Diana MARTINS}

Instituto Politécnico de Leiria - Escola Superior de Educação

e Ciências Sociais

dianafcm@gmail.com

https://orcid.org/oooo-0002-2504-3264

\section{Nídia MESQUITA}

Instituto Politécnico de Leiria - Escola Superior de Educação

e Ciências Sociais

nidiapm_23@hotmail.com

https://orcid.org/oooo-0002-1582-6425

\section{María José GAMBOA}

Instituto Politécnico de Leiria - Escola Superior de Educação e

Ciências Sociais

Centro de Estudos em Educação e Inovação (CI\&DEI)

mjgamboa@ipleiria.pt

https://orcid.org/oooo-0oo3-3273-4773

Resumen: Teniendo presente la función social de la educación y la necesidad de un enfoque pedagógico integrado en la educación preescolar en acorde con un desarrollo integral y holístico del niño, presentamos un proyecto de intervención educativa, construido y dinamizado en el marco de la formación inicial y profesionalización de educadores infantiles. El proyecto "Vamos a descubrir Príncipes y Princesas... Castillos y Dragones" se basa en una pedagogía infantil que valoriza la primacía de la voz del niño, constructora activa de su recorrido de aprendizaje, pensada en una dinámica de (ínter) acción integradora centrada en el enfoque STEAM. El estudio llevado a cabo adoptó la forma de un estudio de caso y los datos recogidos permiten reconocer las contribuciones del proyecto anclado en la pedagogía STEAM para el aprendizaje de los niños y para una acción reflexiva de fuerte carácter formativo para las educadoras involucradas.

A partir de la propuesta elaborada, se pudo entender la acción de STEAM teniendo en cuenta la acción del niño, elemento principal de la acción pedagógica, a partir de la resolución de problemas. Asimismo, se pudo constatar la promoción del aprendizaje a través de esta metodología a nivel cognitivo, con 
el desarrollo de la innovación, la implicación, la creatividad, el trabajo en equipo y la comunicación.

Palabras clave: STEAM; prácticas participativas; educación preescolar.

\section{LEARNING AND GROWING UP WITH STEAM:} A PROJECT EXPERIENCE IN KINDERGARTEN

Abstract: This paper presents an educational intervention considering the social function of education and the need for an integrated pedagogical approach in kindergarten education for the holistic development of the child, built and streamlined within the framework of initial training and professionalization of childhood educators. The project "Let's discover Princes and Princesses ... Castles and Dragons" is based on a childhood pedagogy that values the primacy of the child's voice, active builder of their own learning path, designed in a dynamic of integrative (inter) action centred on the STEAM approach. The data collected for this case study highlights the contributions of the project anchored in the STEAM pedagogy for children's learning and for a reflexive action with a strong formative tendency for the involved educators. From this proposal, it was possible to understand the action (not sure about this) of STEAM considering the children's agency, placing them as the main element of the pedagogical action, based on problem solving. On the other hand, it was possible to verify the promotion of learning through the methodology at the cognitive level, with the development of innovation, involvement, creativity, teamwork, and communication.

Keywords: STEAM; participative practices; kindergarten education.

\section{APRENDRE I CRÉIXER AMB STEAM: UNA EXPERIÈNCIA DE DISSENY A L'ESCOLA BRESSOL}

Resum: Tenint present la funció social de l'educació i la necessitat d'un enfocament pedagògic integrat en l'educació preescolar d'acord amb un desenvolupament integral $i$ holístic del nen, presentem un projecte d'intervenció educativa, construït i dinamitzat en el marc de la formació inicial i professionalització d'educadors infantils. El projecte "Descobrim Prínceps i Princeses... Castells i Dragons" es basa en una pedagogia infantil que valora la preeminència de la veu del nen, constructora activa del seu recorregut d'aprenentatge, pensada en una dinàmica d'(inter)acció integradora centrada en l'enfocament STEAM. Es tracta d'un estudi de cas en què les dades recollides permeten reconèixer les contribucions del projecte que segueix la pedagogia STEAM per a l'aprenentatge dels nens i per a una acció reflexiva de fort caràcter formatiu per a les educadores involucrades. A partir de la proposta elaborada, es va copsar l'acció STEAM tenint en compte l'acció del nen, element principal de l'acció pedagògica, a partir de la resolució de problemes. També es va poder constatar la promoció de l'aprenentatge a través d'aquesta metodologia en l'àmbit cognitiu, amb el desenvolupament de la innovació, la implicació, la creativitat, el treball en equip i la comunicació.

Paraules clau: STEAM; pràctiques participatives; educació preescolar.

\section{Introducción}

En Portugal, la Educación Preescolar está regulada por un documento, reformulado en 2016, que pretende orientar las prácticas de este contexto que se denomina Directrices Curriculares para la Educación Preescolar (OCEPE) -

Nestas orientações considera-se a educação de infância um ato intencional baseado na observação, planificação, ação e avaliação integradas, em que a criança é sujeito e agente do seu processo educativo (Marchão, Porto y Coelho, 2019, p. 106). 
En las OCEPE, vemos reflejados los fundamentos y principios que rigen la educación infantil $y$, en particular, el papel del niño, la forma de aprender y de desarrollarse, el currículo y las respuestas singulares que se deben promover.

Considerando que se trata de una etapa fundamental en el desarrollo del niño, la educación preescolar lanza desafíos constantes a los educadores. En el marco de estos desafíos y partiendo de los principios y presupuestos de la pedagogía infantil y del marco jurídico orientador de prácticas educativas en el contexto de la educación preescolar en Portugal, se presenta en este artículo un proyecto que pretende colocar el desarrollo integral y holístico del niño en el corazón de la acción educativa. Así, teniendo en cuenta fundamentos y principios, que colocan al niño en el centro de la acción educativa, el currículo como algo integrador y contextualizado y el desarrollo y aprendizaje como singular y adscrito a cada niño, se ha concebido, con los niños, una experiencia pedagógica basada en la metodología STEAM.

En este artículo se pretende, por tanto, relatar una experiencia integradora con niños de tres, cuatro y cinco años, centrada en los principios y fundamentos de la pedagogía infantil y en la metodología STEAM, y reflexionar sobre los aprendizajes que de ella resultan tanto en la perspectiva de desarrollo del niño como en la del educador en formación.

\section{Discusión teórica}

\section{Educación Preescolar: entre el currículo y la acción educativa y pedagógica}

La educación de los niños es un proceso complejo que debe ser tomado en serio para el desarrollo y el aprendizaje que surgen del contexto y de la vida de cada uno de los niños.

A lo largo de los años, la Educación Preescolar ha asumido una mayor importancia y relevancia, llevando al desarrollo de investigaciones que colocan el papel del niño y su competencia como inicio de la acción educativa. En este sentido, en Portugal, ha surgido un conjunto de documentos legales que orientan la educación de los más jóvenes.

(...) A educação pré-escolar é a primeira etapa da educação básica no processo de educação ao longo da vida, sendo complementar da ação educativa da família, com a qual deve estabelecer estreita relação, favorecendo a formação e o desenvolvimento da criança, tendo em vista a sua plena inserção na sociedade como ser autónomo, livre e solidário (Lei $\mathrm{n}^{\mathrm{0}} 5 / 97$, de 10 de Fevereiro).

En este marco jurídico, destaca la Ley Marco de Educación Preescolar que enmarca

(...) a organização das Orientações Curriculares para a Educação Pré-Escolar (OCEPE, despacho $n^{o} 5220 / 97$ de 10 de Julho) que se constituem como um conjunto de princípios gerais de apoio ao educador na tomada de decisões sobre a sua prática, isto é, na condução do processo educativo a desenvolver com as crianças (Circular n.17/DSDC/DEPEB/2007, p.1). 
Las Orientaciones Curriculares para la Educación Preescolar (OCEPE), reformuladas en 2016,

(...) baseiam-se nos objetivos globais pedagógicos definidos pela referida Lei e destinam-se a apoiar a construção e gestão do currículo no Jardim de Infância, da responsabilidade de cada educador/a, em colaboração com a equipa educativa do estabelecimento educativo/agrupamento de escolas (p. 5).

Estos objetivos pedagógicos asientan al niño, al aprendizaje y su desarrollo en los siguientes fundamentos y principios de la pedagogía para la infancia (Silva et al., 2016):

O desenvolvimento e aprendizagem como vertentes indissociáveis no processo de evolução da criança (...); Reconhecimento da criança como sujeito e agente do processo educativo (...); Exigência de respostas a todas as crianças; Construção articulada do saber (Silva et al., 2016, pp. 8-10).

La apropiación de estos fundamentos y principios da la libertad al educador de aprovechar metodologías que asumen características participativas, dado que, estas

(...) conceptualizam a criança como uma pessoa com agência, não à espera de ser pessoa, mas que participa como pessoa na vida da família, da escola, da comunidade. (...) O aluno é envolvido nos processos de ensino-aprendizagem, sendo, assim, um coconstrutor da sua educação” (Oliveira-Formosinho y Formosinho, 2013, p. 20).

Una de las metodologías que pone el énfasis en la imagen del niño y en su complejidad, estructura y singularidad es STEAM (Science, Tecnology; Engineering; Art and Math).

STEAM - “(...) Education emerge as a new pedagogy (...) in Response to the need to Increase student Learning interest Innovation Ability and Practice Skills in STEAM Fields” (Mengmeng et al., 2019, p. 485).

Los estudios realizados en esta metodología muestran las potencialidades de una acción pedagógica de naturaleza integradora cuyas prácticas exploratorias, de descubrimiento y cooperación favorecen la construcción activa de conocimiento por parte de cada niño.

La metodología STEAM surge de una cuestión, de una duda o solo de un interés de uno o varios niños y desarrolla de forma holística e integradora las diferentes áreas que la constituyen. Efectivamente, siguiendo una lógica de resolución de problemas y construcción de proyectos, a través de STEAM "Children constantly explore and experiment, working with all kind of tools, problem solving, and comparing things. That's why teachers can offer STEAM learning opportunities everywhere" (Sharapan, 2012, p. 37).

\section{Metodología}

En el ámbito de las actividades propuestas en las prácticas pedagógicas en Jardín de Infancia, de la Maestría en Educación de Preescolar, en la Escuela de Educación y Ciencias Sociales de Leiria (Por- 
tugal), y en un marco de reflexión sobre la importancia de las metodologías que responden a pedagogías participativas, hemos considerado pertinente relatar reflexivamente la experiencia vivida con niños de tres, cuatro y cinco años, durante tres meses de práctica docente supervisada, y evidenciar sus aprendizajes. El punto de partida, además de los principios rectores de STEAM, fue la siguiente pregunta: ¿Qué aprendizajes experimentan los niños en el aprovechamiento de un proyecto basado en la metodología STEAM?.

El enfoque de investigación que mejor se adapta a este estudio es el cualitativo, con carácter descriptivo (Carmo y Ferreira, 1998).

En este sentido, usaremos el estudio de caso (Amado, 2014, p. 124). El caso en cuestión es un trabajo realizado en una sala de niños de tres, cuatro y cinco años, en el contexto descrito.

Los participantes son veinticinco niños (12 niños y 13 niñas) de las citadas edades que asisten a la enseñanza preescolar en una institución pública portuguesa.

Los instrumentos de recopilación de datos utilizados fueron la observación directa y participante, con dos tipos de registro: el diario de bitácora y el registro fotográfico. Durante el desarrollo del proyecto, se procedió al registro descriptivo de las propuestas y de los momentos transcurridos del mismo, así como la participación de los niños y un registro fotográfico. Los datos fueron tratados mediante el análisis de contenido(Carmo y Ferreira, 1998).

\section{Contexto del proyecto}

El proyecto "Vamos a descubrir Príncipes y Princesas... Castillos y Dragones" surgió de los intereses de los niños generados en los momentos de lectura de narrativas infantiles cuyos personajes son reyes, príncipes, princesas y ambientes que representan castillos medievales. Este interés suscitó la curiosidad de los niños que deseaban comprender cómo se vivía en un castillo, cómo era un castillo por dentro y quién vivía en él.

Esta curiosidad contagió al grupo e hizo surgir la construcción de un castillo en el aula, convirtiéndola en un ambiente propicio al desarrollo de la magia y del deslumbramiento en torno a la época medieval.

Este deslumbramiento, unido a la vivencia de los niños en torno al castillo, hizo surgir diálogos entre los niños que encuadraban momentos de juego libre. Este juego de imitación de príncipes y princesas dio lugar a dos nuevas imágenes que pasaron a vivir con los niños: el Rey Patchim Patchum y la Reina Patcha Patcho.

Estos dos personajes (el rey y la reina) surgen como incitadores de desafíos, propuestas y actividades, y que comunicaban con el grupo a través de cartas. Estas cartas son una representación de la correspondencia real, y se guardaban en un baúl. El baúl fue confeccionado por los niños, dada la necesidad de crear un medio de conexión entre el rey y la reina y el grupo de niños. 


\section{La Agencia de los Niños en la metodología STEAM: ejecución del Proyecto "Vamos a descubrir Príncipes y Princesas... Castillos y Dragones"}

La ejecución del proyecto comenzó con la construcción del baúl de la sala. En una conversación matinal, los niños entendieron la necesidad de crear un medio de conexión entre los reyes y el grupo, sugiriendo la construcción de un baúl. Tras la decisión sobre el modo de construcción del baúl, él grupo se dividió en pequeños grupos y su acción fue pensada en una lógica de pedagogía diferenciada. Así, por un lado, los niños más mayores pensaron e idearon el modo de medir, así como las medidas que se aplicarían en la planta y en la confección del baúl y, por otro, los niños más jóvenes decidieron la técnica plástica que se adoptaría para pintar el baúl, así como su decoración. Esta propuesta exploraba a la vez conceptos y competencias matemáticas, en lo que se refiere a las medidas, y exploraba las artes, con el trabajo de pintura del baúl. De este modo, en el ámbito de las matemáticas, partiendo de la premisa de que en la primera fase de exploración didáctica con medidas

com crianças mais pequenas, as tarefas que devem ser propostas incluem objetos concretos, a partir dos quais observam as suas características e, manipulando-os, comparam um ou mais dos seus atributos (Mendes y Delgado, 2008, p. 46),

los niños pudieron acceder a un baúl acabado con el fín de observar, manipular y pensar en las medidas y formas, como se muestra en la Figura 1. Después de ese momento de conversación y reflexión, los niños, con base a la premisa de que la segunda fase de exploración didáctica con medidas "diz respeito à utilização de uma unidade de medida, seja ela natural ou padronizada (...)" (Mendes y Delgado, 2008 , p. 46), eligieron para instrumento de medida un objeto de madera de forma plana que existía en la sala y definieron la longitud y la anchura del baúl. Tras estas decisiones, los niños, partiendo de la premisa de que la tercera fase de exploración didáctica con medidas "(...) se refiere al uso de un instrumento de medida” (Mendes y Delgado, 2008, p. 46), iniciaron la construcción del baúl, usando como materiales una espuma y tijeras, como se muestra en la Figura 2.

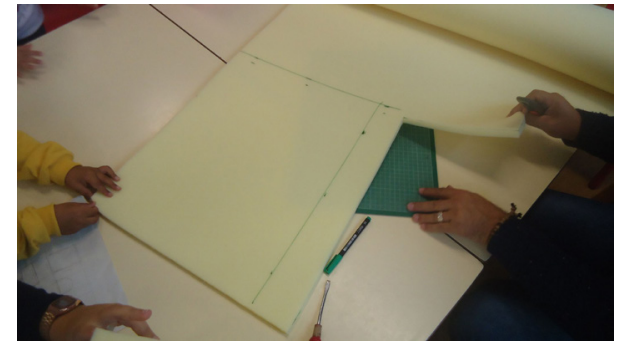

Figura 1. Niños tachando las medidas del baúl. Fuente: Propia.

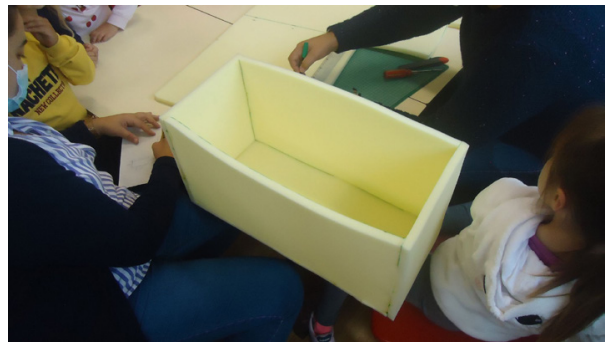

Figura 2. Niños pegando el baúl de esponja. Fuente: Propia.

En lo referente a las técnicas artísticas, los niños utilizaron la pintura, por ser

(...) uma experiência essencial para todas as crianças, porque contribui para o desenvolvimento total (...) [e por implicar] descoberta. Esta descoberta encontra-se nos gestos diversificados, que provocam uma variedade imensa de marcas. (...) São descobertas sensoriais, treino gestual, observações e reflexões que conduzem a aprendizagens (Santinha, 2004, pp. 53-54). 
Después de acabar el baúl, el Rey Patchim Patchum y la Reina Patcha Patcho, iniciaron la correspondencia con el grupo de niños y el envío de desafíos, propuestas y actividades. Para agradecer el trabajo de los niños en la construcción del baúl, el Rey les envió una carta advirtiéndoles de que les haría un regalo. Este regalo estaría escondido en algún lugar de la escuela y solo se podría encontrar superando tres desafíos: el montaje de un rompecabezas, como se muestra en la Figura 3, la identificación de un elemento natural, como se muestra en la Figura 4, y la respuesta a una adivinanza, como se muestra en la Figura 5. La creación del reto con el rompecabezas permitió la exploración del dominio de las matemáticas, en particular el razonamiento lógico y partió de la premisa de que

A disponibilidade e a utilização de materiais manipuláveis (colares de contas, cartões padronizados, tangram, material de cuisenaire, miras, puzzles, dominós, legos, etc.) são um apoio fundamental para a resolução de problemas e para a representação de conceitos matemáticos (Silva et al., 2016, p. 75).

La identificación del elemento natural (agujas de pino) exploró el área de las ciencias y partió de las premisas de que "(...) a estimulação sensorial, pode, por sua vez, promover o rápido desenvolvimento do cerebro" (Papalia et al., 2001, p. 168) y de que

O/A educador/a promove (...) aprendizagens [na área de conhecimento do mundo] quando, por exemplo (...) Cria uma área das ciências com materiais diversos que incentivem as explorações e a experimentação:

- materiais naturais - rochas, folhas, madeiras, conchas, plantas ou suas partes (caules, folhas, flores, frutos, raízes), etc.

- materiais habituais na vida corrente - recipientes, colheres, funil, etc.

- materiais mais específicos (...) (Silva et al., 2016, p. 87).

La adivinanza permitió explorar el dominio del lenguaje oral y de la escritura y partió de la premisa de que:

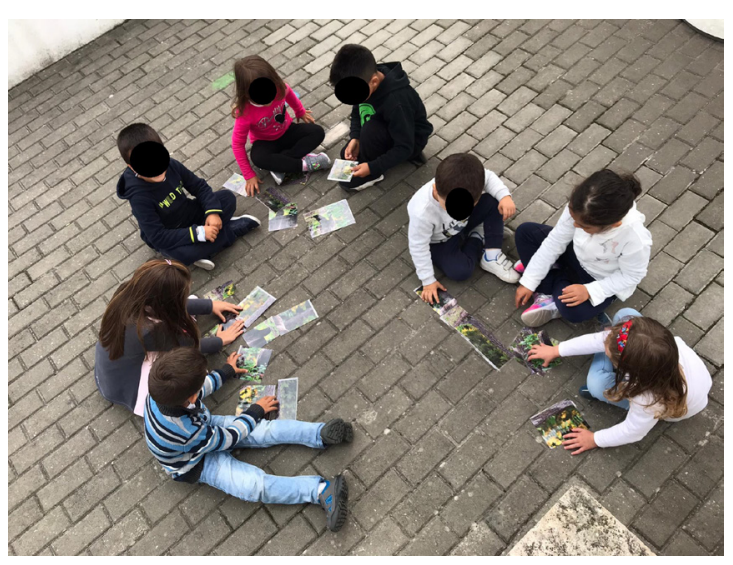

Figura 3. Niños realizando el rompecabezas.

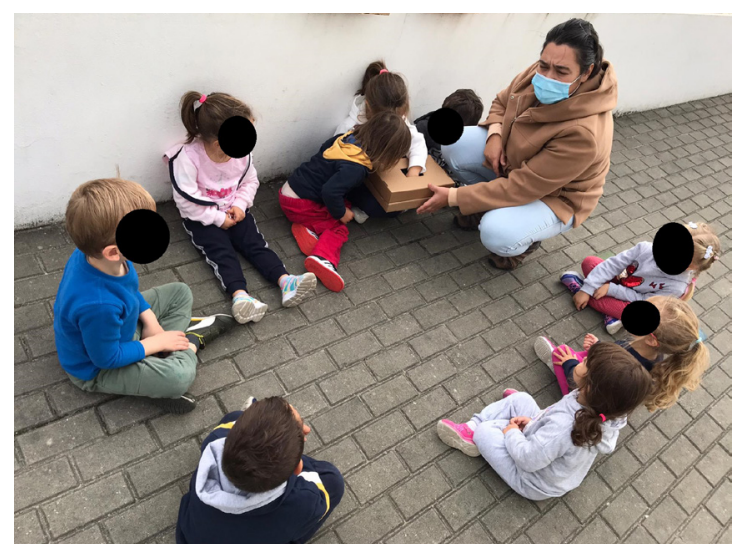

Figura 4. Niños metiendo la mano en una caja y sintiendo las agujas de pino. 


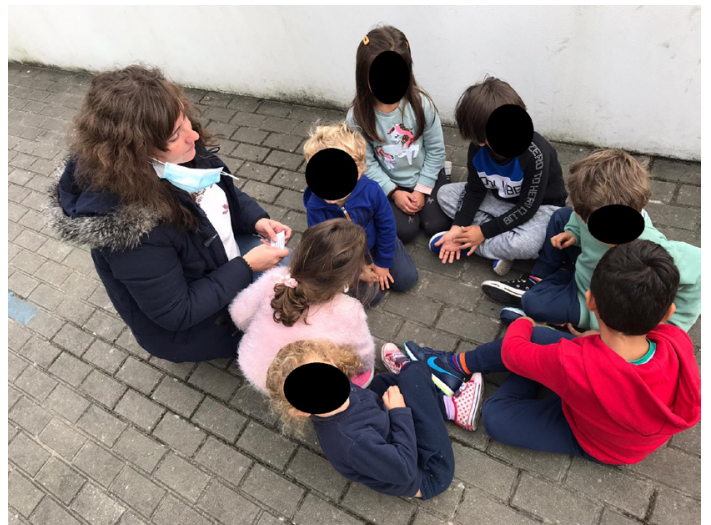

Figura 5. Niños pensando en la adivinanza.

Tras la realización de los desafíos y su superación, los niños recibieron tres pistas, como sé muestra en la Figura 6, que les permitieron concluir que el regalo del Rey estaba escondido en el Jardín de los Olivos (un espacio del Jardín de Infancia). Los niños se dirigieron al lugar, exploraron todos los rincones y descubrieron el libro Vamos a la caza del oso de Michael Rosen y Helen Oxenbury, como se muestra en la Figura 7. Después de la lectura de la historia, como se muestra en la Figura 8, los niños disfrutaron de la exploración de las áreas artística y del conocimiento del mundo en una propuesta lanzada por el Rey, como se muestra en la Figura 9. El monarca pidió ayuda a los niños para que fuesen a la búsqueda del oso que se escondía en el bosque. Esta propuesta permitió él acceso a juegos exploratorios que pusieron en acción la premisa de que los actos de representación de uno mismo y de los demás, en situaciones reales e imaginarias, son un poderoso instrumento para el desarrollo personal y social del ser humano (Kowalski, 2008), así como una excelente manera de

(...) contacto com seres vivos e outros elementos da natureza e a sua observação (...) [sendo] experiências muito estimulantes para as crianças, proporcionando oportunidades para refletir, compreender e conhecer as suas características, as suas transformações e as razões por que acontecem”(Silva et al., 2016, p. 90).

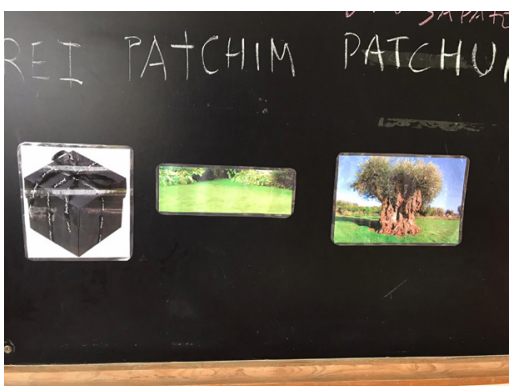

Empezando por la izquierda, Figura 6. Pistas que recibieron los niños. Figura 7. Niños buscando el regalo.

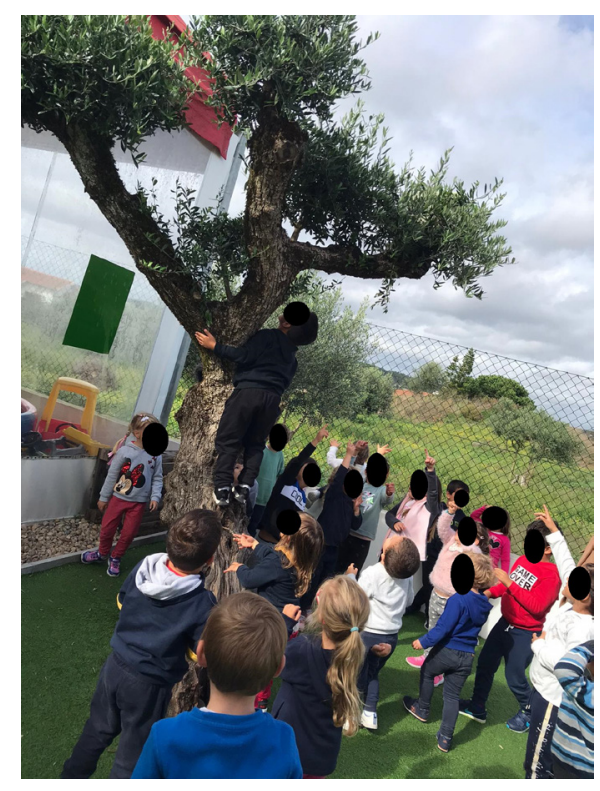



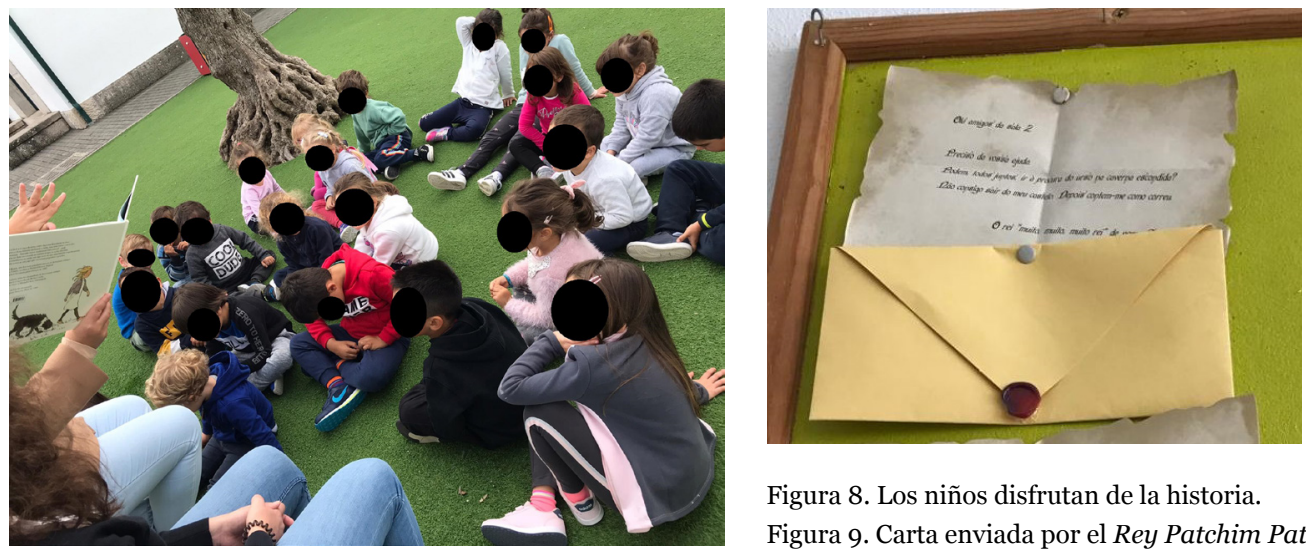

Figura 8. Los niños disfrutan de la historia.

Figura 9. Carta enviada por el Rey Patchim Patchum.

Terminada esta secuencia didáctica, se inició otro momento del proyecto en el que el Rey invitó a los niños a un baile real. Este baile sugerido por el Rey, surgió del interés de los niños en conocer al Rey. Este baile real fue realizado para que el Rey se presentara a los niños y conllevaba una condición especial: tenían que llevar una corona en la cabeza. Los niños, en una conversación en grupo, decidieron los materiales que se utilizarían, habiendo quedado claro que querían hacer las coronas usando esponja. Cada niño escogió la forma de su corona y pudo elegir pinturas y accesorios brillantes, pompones, cintas, etc.

A partir de ese momento se inició la construcción de las coronas. Los niños comenzaron a buscar en Internet cómo son las coronas de los reyes, cómo las usaban y su simbolismo. Esta propuesta permitió la exploración del área del conocimiento del mundo que, en la Educación Preescolar, engloba el medio físico y social, además del mundo tecnológico y la utilización de las tecnologías, con el uso del ordenador. Saber más acerca de los tiempos de los reyes, de las costumbres y del simbolismo y función de la corona, partió de la idea de que un aprendizaje esperado para la Educación Preescolar, en esta área social de las ciencias, es establecer una conexión entre el pasado y él presente, teniendo en cuenta situaciones de vida y prácticas culturales (Silva et al., 2016). Por otra parte, se promovió la instalación del ordenador como medio de búsqueda de información teniendo en cuenta las observaciones realizadas en el contexto, entendiendo que los niños utilizaban esta tecnología de forma natural, y partiendo de la idea de que los ordenadores permiten un aprendizaje por la acción, y que “(...) fazem hoje parte da vida de todas as crianças, tanto em momentos de lazer (...), como no seu quotidiano (...)” (Silva et al., 2016, p. 93).

Terminada la búsqueda, los niños, a través del banco de imágenes acopiado, crearon el modelo de corona que deseaban y con la ayuda del adulto dibujaron ese modelo en la esponja, la cortaron y empezaron a pintar. Con esta propuesta los niños, exploraron el subdominio de las artes visuales, utilizando la pintura, como se muestra en la Figura 10, y la creatividad durante el proceso de construcción y adorno. El adorno de la corona, como se muestra en la Figura 11, se llevó a cabo a partir de diversos materiales, seleccionados por los niños, y partió de la premisa de que "as crianças têm prazer em explorar e utilizar diferentes materiais que lhe são disponibilizados (...) de modo a desenvolverem a imaginação e as possibilidades de criação” (Silva et al., 2016, p. 49). 


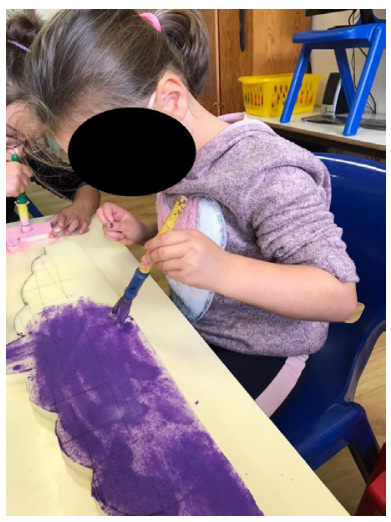

Figura 10. Niño pintando la corona.

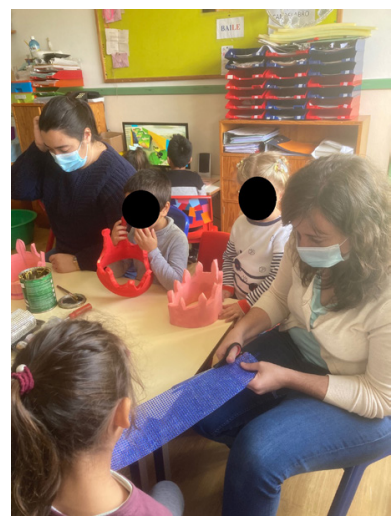

Figura 11. Niños adornando la corona.

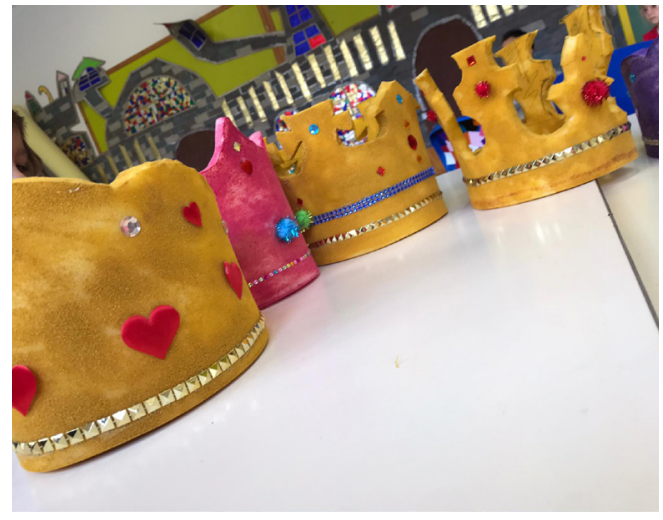

Figura 12 - Coronas para el baile real.

Terminada la confección de las coronas, como se muestra en la Figura 12, se inició la decoración de la sala para recibir al Rey y celebrar el baile real. Com base a la conversación en grupo grande, los niños decidieron colocar un trono para recibir al Rey, como se muestra en la Figura 13, en el centro de la sala y decorar la puerta, como se muestra en la Figura 14, con unas cortinas que simulaban las entradas de los castillos en la época medieval. Así, de casa trajeron trapos, cortinas y accesorios de decoración que recordaban aquellos tiempos, como candelabros, velas, platos, jarras y tazas. El grupo transformó la sala en un Gran Salón, listo para recibir el baile y el Rey, como se muestra en la Figura 15.

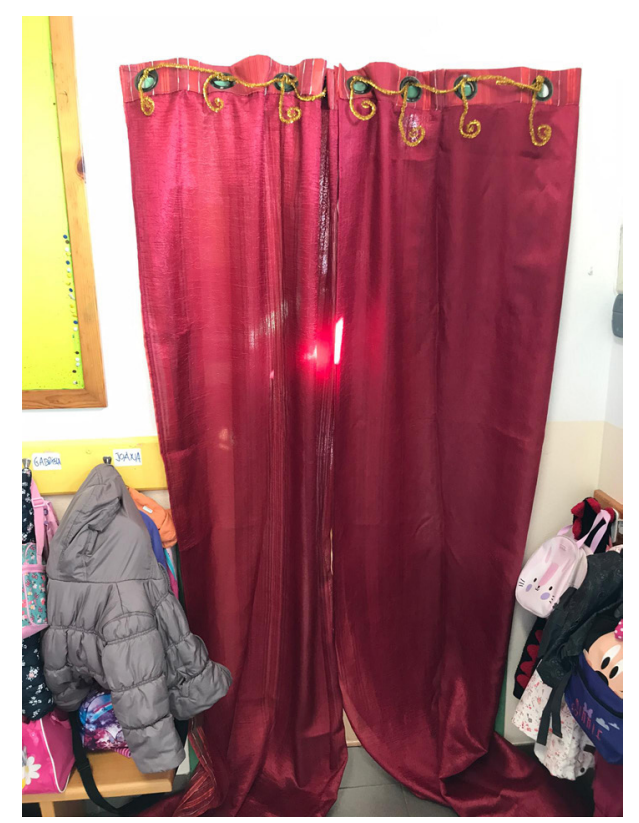

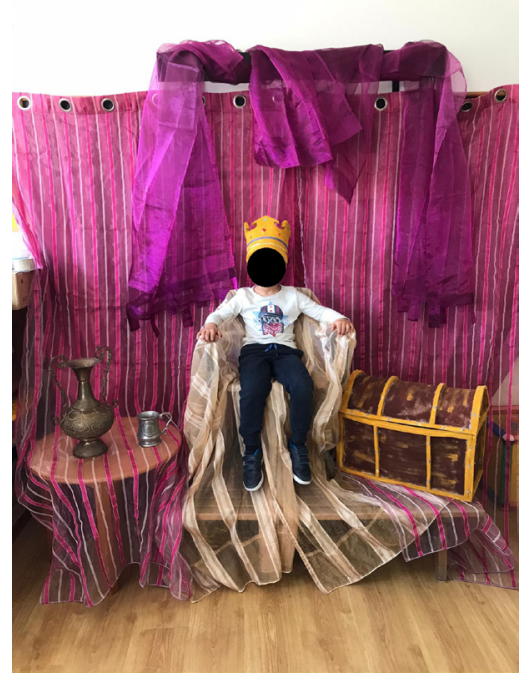

Figura 13. Lugar con el trono del Rey.

Figura 14. Puerta de entrada de la sala. 


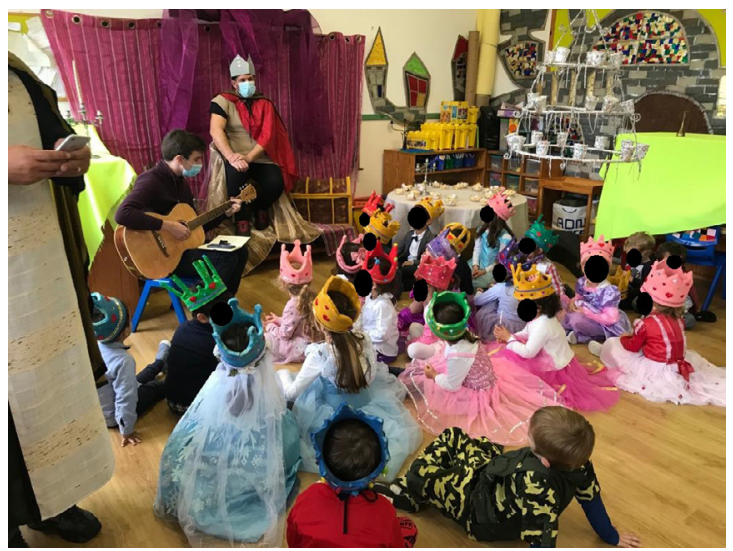

Figura 15. Los niños reciben el Rey Patchim Patchum en el baile real.

Esta propuesta exploró las artes y la creatividad y permitió a los niños confrontar sus ideas y pensar en lo que querían y cómo iban a conseguirlo.

El baile real sirvió como lema para seguir con este proyecto, en la medida en que fue posible comprender que había potencialidades para su ampliación. En el transcurso del baile, los niños mostraron interés en crear otra forma de comunicación con el Rey $y$, a partir de un experimento con robots realizado el año anterior, surgió la idea de construir un robot cartero que llevase las cartas al Rey. Esta propuesta se encuentra todavía en fase de conversación en grupo grande y todavía no se ha llevado a cabo.

\section{Evaluación y aprendizaje STEAM}

Subyace en la construcción de este proyecto el principio de que el "desenvolvimento da criança processa-se como um todo, em que as dimensões cognitivas, sociais, culturais, físicas e emocionais se interligam e atuam em conjunto" (Silva et al., 2016, p. 10). En efecto, la aplicación y realización de este proyecto ha tenido como intención la ampliación de horizontes temporales, el desarrollo de competencias cognitivas en el ámbito lingüístico, de las matemáticas, de las ciencias, de la tecnología, de la ingeniería y de las artes, el desarrollo de competencias actitudinales y la promoción de entornos de asombro, deseo y participación colaborativa, desde una perspectiva de integración de los planes de estudios.

Sin dejar de lado los principios y objetivos de la metodología STEAM, se optó por fusionar las intencionalidades que deben promoverse y explotar el potencial de esta metodología y, en particular, la posibilidad de desarrollar competencias cognitivas, la creatividad y la participación de los niños en la resolución de problemas.

Así, el análisis documental (a través de las fotografías y de los cuadernos de bitácora realizados a lo largo del proyecto) permitió destacar innumerables aprendizajes realizados por los niños. Podemos reseñar ejemplos de una acción participativa autónoma, basada en la creatividad, a través de enunciaciones como "Yo lo hago solo", "Yo puedo hacerlo", "Voy a empezar"; la capacidad de juzgar lo que estaban haciendo, a través de enunciaciones como "Creo que tengo que pintar mejor allí", "Voy a hacerlo así...", "Este lado está mejor que este otro...". Se verifica la confianza en sí mismo 
demostrada por la voluntad de sugerir diferentes propuestas y formas de hacerlas; la resiliencia, a través de actitudes de cara a la frustración y la discapacidad y la sensibilidad estética, a través de actitudes de observación, reflexión y tentativa (Morales, 2004).

En cuanto a la innovación y a la capacidad de resolver problemas, se pudo observar en los niños pensamientos que conducían a diferentes situaciones que formaban parte de su contexto. Efectivamente, los niños sugirieron el uso de materiales diferentes; el uso de estrategias diferenciadas para resolver los problemas a los que enfrentaban, como por ejemplo sugerir el uso de un material específico para las bisagras del baúl y la comparación de la factibilidad de dicho material, o sugerencias de materiales a utilizar para decorar la entrada al salón real, como se muestra en la Figura 16. La comunicación entre el Rey y los niños, que se realiza a través del cofre, en futuro, será sustituido por el robot, lo que permite que los niños entiendan la noción del tiempo con las diferencias en lo referente a la tecnología, la cultura y la sociedad.

\section{Diário de Bordo}

\begin{tabular}{l} 
Diário de Bordo: \\
Data: 09 de novembro de 2020 \\
Local: Sala 2 \\
Período: Manhã (Conversa em grande grupo) \\
Observadora: Diana Martins e Nídia Mesquita \\
\hline \multicolumn{1}{c|}{ Observação } \\
\hline - Perante a necessidade de arranjar uma solução para prender os cortinados à porta, a criança \\
A coloca o dedo no ar e pede para falar; \\
- Desenvolve-se o seguinte diálogo: \\
N: A. O que queres dizer? \\
A: Tenho uma ideia... podiamos pedir ao meu pai aqueles pregos que são assim (faz um movimento \\
com as mãos) e pediamos também o martelo e pregávamos ali naquela parte em cima... ali (levanta-se \\
e aponta para a ombreira da porta). \\
N: Mas A., temos de ver se o teu pai pode emprestar. Consegues falar com ele? \\
A: Ele pode, ele tem lá muitos. \\
N: Mas temos de falar com ele na mesma. E quem é que prega os pregos? \\
A: É fácil... O Manel. \\
N: E se o Manel não conseguir? \\
A: Fazes tu e a Nídia. Ou então podemos pedir à São... Espera... podemos pedir também ao meu pai \\
para vir aqui...
\end{tabular}

Figura 16. Registro de diálogo con uno de los niños.

En cuanto a la participación, pudimos observar en los niños el placer en las propuestas a través de enunciaciones tales como: "Yo quiero hacerlo... ", "Y yo... ¿cuándo me toca?", "Y yo, yo, yo, ...", "Me gusta tanto pintar...", "Me gusta estar con el ordenador...", "¿Puedo hacerlo ahora yo?"; la concentración al invertir tiempo y paciencia para la realización de las propuestas; la persistencia y el compromiso a través de la capacidad de los niños para desarrollar las diferentes propuestas con calma, con voluntad y siempre intentando hacer lo mejor que podían. (Silva et al., 2016)

En lo que refiere al trabajo en equipo y a la comunicación, se pudo comprender la adquisición de competencias en los niños. A través de las conversaciones en grupo grande, a partir de las preguntas que llevaban a la resolución de problemas, las interacciones de los niños en los diferentes momentos del proyecto y las diferentes propuestas, se llegó a la conclusión de que la intención de 
los niños de planificar el trabajo por desarrollar, aprovechando las ideas de todos los niños; la confrontación de los puntos de vista que condujeron a la formulación de ideas en las que todos estaban de acuerdo; la colaboración en grupos pequeños y grupos grandes para la resolución de problemas; la cooperación y la interacción en las diferentes propuestas y la comunicación que llevó al proyecto a "salir de las paredes del aula" y a llegar a las familias y al resto del contexto escolar y el entorno social (Silva et al., 2016), como se muestra en la Figura 17:

Figura 17. Comentarios con los padres mediante la herramienta de WhatsApp

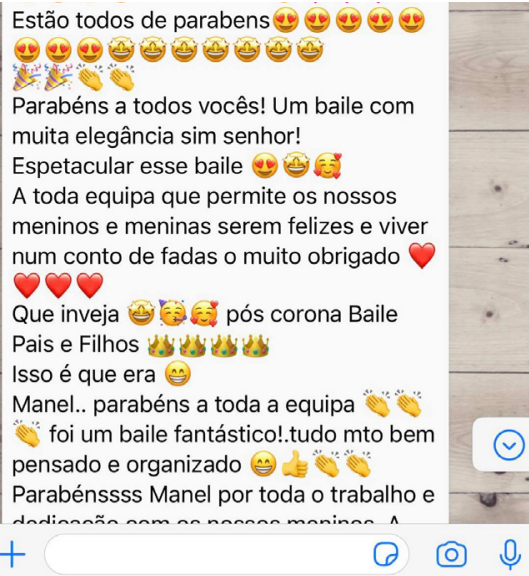

Por último, en lo que se refiere al aspecto cognitivo, se han podido observar diferentes aprendizajes en distintas áreas de STEAM. En el ámbito de la ciencia y la ampliación del vocabulario activo de los niños, estos tomaron conciencia de su identidad y del contexto de pertenencia y establecieron relaciones entre el presente y el pasado, tomando como ejemplo el uso de expresiones como "en el pasado", "en la época medieval", "en aquellos tiempos", "antes" en comparación con "ahora", "en este momento" y "hoy" para comparar costumbres, ropa, comida entre otros. Concretamente, en lo que se refiere al lenguaje, los niños comenzaron a utilizar palabras hasta ahora desconocidas, como candelabro, baile real, mensaje, caballero, armadura, vestimenta, teatro, etc., tal como podemos constatar en el diálogo que transcribimos a continuación:

“A: Diana! Ontem estive a pensar no candelabro e acho que já sei o podemos por lá em cima...

D: Boa A! E qual é a tua ideia?

A: Podemos colocar velas... eu vi isso numa fotografía ontem.

D: Que fotografía?

A: Uma fotografía antiga, que mostrava um salão real do tempo medieval.

D: Podes trazer essa fotografía amanhã para vermos?

A: Sim, eu amanhã trago."

En el ámbito de la tecnología, los niños reconocieron la utilidad del ordenador y su potencial para buscar información y establecer relaciones entre lo que conocen y lo que necesitan saber. En el ámbito de la educación artística, los niños abordaron propuestas que llevaron al desarrollo de la 
creatividad; al desarrollo de la explotación del juego exploratorio con la puesta en escena del baile real y el desarrollo de competencias expresivas mediante propuestas plásticas. Por último, en el ámbito de las matemáticas, los niños desarrollaron capacidades de medición con la construcción del baúl; de conciencia de los números con el recuento de elementos que podrían colocar en la corona y en el surgimiento de operaciones con la percepción de los elementos que tienen y que faltan para construir la corona (Silva et al., 2016), como se pone de manifiesto en las Figuras 18 y 19.

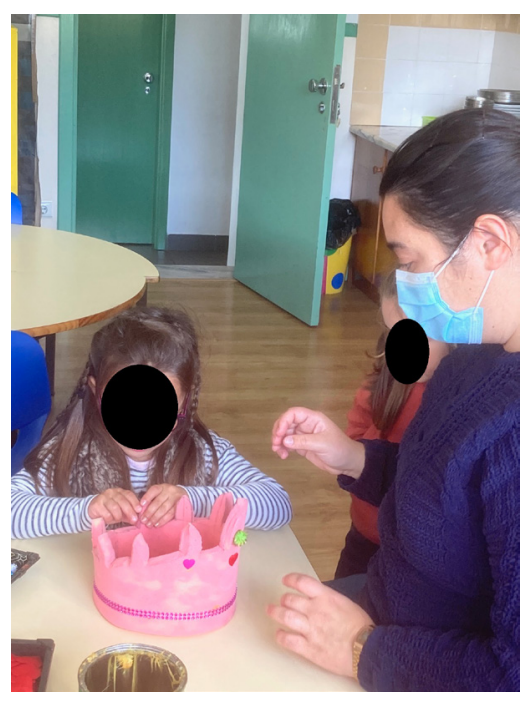

Figura 18. Niño contando las piedras para pegar en la corona.

\section{Diário de Bordo}

\begin{tabular}{l}
\hline Diário de Bordo: \\
Data: 11 de novembro de 2020 \\
Local: Sala 2 \\
Período: Manhã (Construção das coroas) \\
Observadora: Diana Martins e Nídia Mesquita \\
\hline \multicolumn{1}{c|}{ Observação } \\
\hline - A criança M está sentada a criar artisticamente a sua coroa, quando se inicia o seguinte \\
diálogo: \\
D: M queres colocar pedras de que cor? \\
M: Quero estas, as cor-de-rosa. \\
D: Muito bem M. Quantas precisas? \\
M: Vou contar... (coloca o dedo em cada lugar que quer colocar a pedra e conta). Já tenho duas, preciso \\
de mais cinco. \\
D: Muito bem. Queres tirar tu? \\
A: Sim. Vou tirar seis... uma, duas, três... (repete o movimento até retirar seis pedras do recipiente). \\
\hline
\end{tabular}

Figura 19. Registro de diálogo con uno de los niños.

\section{Conclusión}

La realización del proyecto "Vamos a descubrir Príncipes y Princesas... Castillos y Dragones" fue una experiencia de estreno para el contexto formativo en el que se realizó la práctica pedagógica de las futuras educadoras. El uso de la metodología STEAM ha sido pertinente teniendo en cuenta los principios que la guían y la especificidad del grupo de niños involucrado. 
El desarrollo de esta metodología ha puesto de manifiesto la capacidad de actuación de los niños, ya que nació de éstos y de sus intereses el desarrollo del proyecto y la formulación de las propuestas; la integración del currículo, ya que fue posible trabajar de forma holística competencias actitudinales, cognitivas y relacionales y permitió que cada niño actuase de forma singular y única. Del mismo modo, las ciencias, las tecnologías, las ingenierías, las artes y las matemáticas se han convertido en el motor de aprendizaje y desarrollo del pensamiento y sobre la base de que STEAM es la "(...) Response to the need to increase student learning interest innovation ability and practice skills in STEAM fields" (Mengmen et al., 2019, p. 485).

Así, a través de la construcción de la respuesta a la pregunta: "¿Qué aprendizajes ponen de manifiesto los niños en la explotación de un proyecto que tiene como base la metodología STEAM?" se pudo verificar la acción de STEAM y justificar la fusión con los principios y fundamentos rectores de la Pedagogía Infantil en Portugal. Mediante esta pregunta hemos podido concluir que la capacidad de actuación del niño es el motor para el desarrollo curricular, que este currículo debe ser integrador de diferentes áreas y que debe ser promotor de aprendizajes contextualizados y significativos.

La presentación de esta propuesta educativa y la descripción del "actuar" a partir de una metodología STEAM posibilitó la colocación de la voz del niño como elemento principal de la acción educativa y permitió que esta, a través de la explotación, utilizando diferentes estrategias y herramientas, consiguiera a través del pensamiento resolver problemas (Sharapan, 2012). La resolución de problemas es importante en la construcción de conocimientos y permite que los niños aprendan utilizando las diversas áreas del saber (Diniz, 2001).

Del mismo modo, podemos afirmar que la experiencia ha permitido la construcción de diferentes aprendizajes cognitivos por parte de los niños en las diferentes áreas de STEAM, en cuanto a la creatividad, la innovación, la participación, el trabajo en equipo y la comunicación.

En efecto, el contexto preescolar ocupa un puesto de primacía para estas experiencias, pues se permite que el asombro y la magia que rodean determinados mundos literarios traspásenlas páginas de las historias al mundo de los niños, sirviendo como lema para una práctica más participativa que lleva al aprendizaje integrado y al desarrollo holístico de competencias.

La dinamización del proyecto con los niños favoreció, para los educadores en formación, un tiempo - espacio de reflexión sobre modos creativos de educar para la vida, a través de la pedagogía STEAM.

Estos modos creativos de promoción de una educación para la vida se reflejan en el papel del educador en esta metodología que se basa en una práctica participativa. Así, a través de las reflexiones realizadas a lo largo del proyecto, se llegó a la conclusión que la acción del educador pasa por organizar, mediar y facilitar la acción de los niños, teniendo como base su singularidad y sus especificidades, promover los momentos de charla que faciliten la activación de la imaginación y de la creatividad, así como el pensamiento en grupo y la aceptación de las diferentes opiniones y formas de pensar y la creación de situaciones prácticas que lleven a la integración holística del currículo en una metodología como STEAM. 
Por último, se pudo poner de manifiesto la importancia del conocimiento profundo de los intereses de los niños y de los aspectos motivacionales, para llegar a construir con seducción y magia un proyecto con y a partir de los niños. También fue perceptible la importancia de la fundamentación teórica y del poder reflexivo para lograr una sólida articulación entre los fundamentos y los principios de la Pedagogía Infantil y la metodología STEAM.

\section{Referencias}

Amado, J. (2014). Manual de investigação qualitativa em educação. Imprensa da Universidade de Coimbra.

Carmo, H. y Ferreira, M. M. (1998). Metodologia da investigação: Guia para Auto-aprendizagem. Universidade Aberta

Circular n. ${ }^{0}$ 17/DSDC/DEPEB/2007 - Gestão do Currículo na Educação Pré-Escolar. Lei Quadro da Educação Pré-Escolar n. ${ }^{0}$ 5/97 de 10 de fevereiro. Diário da República n. ${ }^{\circ} 34$ - Série I-A. Assembleia da Républica.

Diniz, M. (2001). Resolução de Problemas e Comunicação. En K. Smole, M. Diniz, C. Cavalcanti, C. Chica, E. Milani, P. Candido y R. Stancanelli (Eds.), Ler, escrever e resolver problemas: Habilidades básica para aprender matemática (pp. 87-97). Artmed.

Kowalski, I. (2008). ... e a Expressão Dramática. Instituto Politécnico de Leiria, Escola Superior de Educação de Leiria.

Marchão, A. d., Porto, S. y Coelho, T. (2019). Abordagem pedagógica integrada na educação pré-escolar: o projeto KiitoS@21st Century Preschools. Investigar em Educação (9/10), 105-119. http://pages.ie.uminho.pt/inved/index.php/ie/article/view/160/160

Mendes, M.F. y Delgado, C.C. (2008). Geometria: Textos de apoio para educadores de infância. Direção Geral de Inovação e Desenvolvimento Curricular (DGIDC).

Mengmeng, Z., Xiiantong, Y. y Xinghua, W. (2019). Construction of STEAM curriculum model and case design in kindergarten. American Journal of Educational Research, 7(7), 485-490. https://doi.org/10.12691/education-7-7-8

Oliveira-Formosinho, J., y Formosinho, J. (2013). A perspetiva educativa da Associação Criança: A Pedagogia-em-Participação. En J. Oliveira-Formosinho (Ed.), Modelos curriculares para a educação de infância: Construindo uma práxis de participação (pp. 25-60). Porto Editora.

Papalia, D. E., Olds, S. W. y Feldman, R. D. (2001). O mundo da criança. McGraw-Hill, LDA.

Santinha, M. E. (2004). A prática da expressão plástica no jardim de infância. Ensinarte: Revista das Artes em Contexto Educativo, 43-65.

Sharapan, H. (2012). From STEM to STEAM: How Early Childhood educators can apply Fred Rogers' approach. Young Children, 67(1), 36-40.

Silva, I. L., Marques, L., Mata, L. y Rosa, M. (2016). Orientações Curriculares para a Educação PréEscolar. Ministério da Educação / Direção Geral da Educação (DGE). 